\title{
SWOT Analysis and Discussion on the Online Teaching Mode of Engineering Mechanics in the Background of COVID-19
}

\author{
Yu Dong, ${ }^{1,}$, *
}

\author{
${ }^{I}$ School of Management Science and Engineering, Shandong Technology and Business University, Yantai, Shandong, \\ China \\ *Corresponding author e-mail: dongyu1987@126.com
}

\begin{abstract}
With the rapid development of mobile Internet and big data, the traditional teaching mode continues to transform. The hybrid teaching mode based on various intelligent teaching platforms (tools) has promoted the in-depth reform of educational informatization. Influenced by the global spread of COVID-19, the online teaching mode ushered in a new development opportunity in order to ensure the normal teaching order during the period of epidemic prevention and control. Taking the online teaching mode of engineering mechanics as an example, based on SWOT analysis method, this paper makes a comprehensive, systematic and accurate research on the online teaching mode of engineering mechanics from four aspects: advantages, disadvantages, opportunities and challenges, and puts forward corresponding countermeasures and improvement measures according to the research results, so as to further promote the improvement and development of the online teaching mode.
\end{abstract}

Keywords: COVID-19, engineering mechanics, online teaching, SWOT analysis, reform in education.

\section{INTRODUCTION}

With the rapid development of the information society, teaching techniques and methods continue to be enriched and improved, and smart teaching platforms such as MOOC, Xuetang Online, Wisdom Tree, Superstar Curtain Course, and other smart teaching tools such as Rain Class and Class Cube are popularized. It has triggered a new round of classroom teaching model reform, and also put forward higher requirements for education informatization. The novel coronavirus pneumonia outbreak has become a global pandemic, with COVID-19's sudden development. In March 11, 2020, the outbreak of the new crown pneumonia outbreak was reported. The outbreak of the novel coronavirus pneumonia has also affected traditional teaching mode. In order to better prevent and control the epidemic situation, under the unified arrangement of the Central Committee of the CPC, the State Council and the Ministry of education, the University responded positively to the requirement of "stopping classes, not stopping teaching and stopping classes, not stopping learning", and taking students as the center, and actively promoted the development of online teaching mode [1-
2]. Engineering mechanics is a basic course for engineering majors in applied universities. The mastery and application of engineering mechanics knowledge directly affect students' practical application ability [3]. Taking the teaching practice of the online teaching mode of engineering mechanics in the spring of 2020 in Shandong Technology and Business University as an example, this paper analyzes and discusses the online teaching mode of engineering mechanics by using SWOT analysis method, so as to better carry out the mixed teaching of follow-up engineering mechanics.

\section{CONSTRUCTION OF ONLINE TEACHING MODE OF ENGINEERING MECHANICS}

In order to realize the migration and integration from "offline classroom at school" to "online classroom at home", build the organization, management and feedback system of online teaching, ensure the quality and efficiency of online teaching of engineering mechanics, take into account the network fluency and network congestion emergency plan, combined with the characteristics of different majors of Shandong Institute

Project support: the Youth Foundation of Shandong Technology and Business University(Project No. 2015QN014), the PhD Research Startup Foundation of Shandong Technology and Business University(Project No. BS201522). 
of technology and the differentiated requirements for engineering mechanics courses, The online teaching of Engineering Mechanics adopts a new online teaching mode of Engineering Mechanics integrating "teaching, learning, investigation, practice and thinking", and can realize the supervision and management of students' online learning in the whole process of "before class, during class and after class". The online teaching mode of engineering mechanics is shown in Figure 1.

\section{SWOT ANALYSIS OF ENGINEERING MECHANICS ONLINE TEACHING MODE}

\subsection{Learning advantages of the Online \\ Teaching Mode of Engineering Mechanics}

(1) Break the limitation of space and time

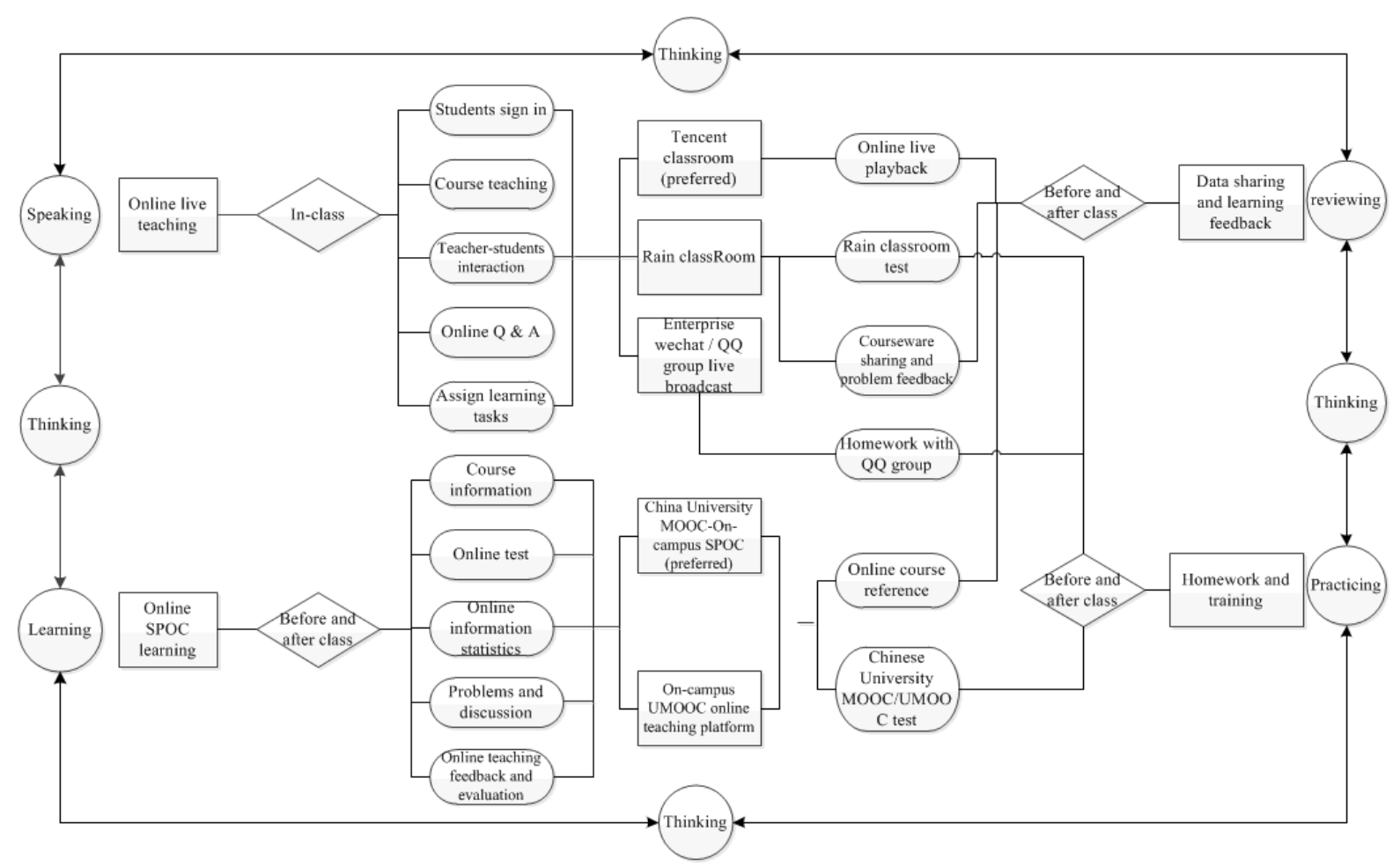

Fig.1 "Multidimensional integration" online teaching mode of engineering mechanics

(2) Construction of efficient "teaching learning" environment

The two main factors to be considered in the construction of Engineering Mechanics online teaching model are teachers' teaching and students' learning. Through the construction of online live broadcast teaching mode, teachers integrate the use of rain classroom intelligent teaching mobile terminal in the process of online live broadcast, and flexibly move the offline classroom rain classroom intelligent teaching process online, so as to maximize students' classroom interaction and participation. Through the construction of online autonomous learning mode, in addition to participating in online live teaching in class, students can also conduct autonomous learning, consolidation,
During the epidemic period, the construction of the "multidimensional and integrated" online teaching mode of Engineering Mechanics moved the whole process of offline teaching to the online, thus breaking the dependence of students and teachers on specific space in the process of learning and teaching, and the implementation of the teaching process is no longer limited to the campus classroom. In addition, combined with the characteristics of engineering mechanics course, engineering mechanics is highly theoretical and closely related to engineering practice, which requires students to have good logical thinking ability. Learning in traditional classroom is far from enough, and the construction of Engineering Mechanics online teaching mode breaks the time limit for students to learn engineering mechanics course. 
data and online teaching platform. Through the whole process of students' learning data and students' synchronous and asynchronous learning feedback and teaching evaluation, Teachers can timely adjust teaching methods and methods, with the help of the feedback of students' objective learning data in the whole process, so as to realize the visualization of the whole process assessment of teaching activities.

\subsection{Disadvantages of the Online Teaching Mode of Engineering Mechanics}

(1) The functions of intelligent teaching tools and online platform need to be further improved

The construction of "multidimensional integration" engineering mechanics online teaching mode is inseparable from the support and assistance of intelligent teaching tools and online education platform. Because different intelligent teaching tools have different emphases and their own shortcomings, different teachers will choose different live broadcasting tools and online teaching platforms for various courses, so that students need to prepare various intelligent teaching tools in advance in the process of learning relevant courses. A variety of intelligent teaching tools increase the burden on students' learning. Teachers and students have higher and higher demand for intelligent teaching tools and online platforms integrating various functions.

(2) The limitations of learning terminals and the differentiated impact of network environment

Due to the different learning conditions of students, the learning tools they can use are also different. The use of computers, tablets, notebooks and mobile phones will greatly help the development of online courses, while a single mobile phone will have a little difficulty in the process of live broadcasting and online autonomous learning. At the same time, it will also face various software apps required by the rich teaching process of different courses. In addition, the development of Engineering Mechanics online teaching activities also has certain requirements for the network environment. As teachers and students teach and study online at home, the stability and fluency of the network and the carrying capacity of intelligent teaching tools and online platforms will directly affect the progress of online teaching activities. At the beginning of the spring of 2020, the online teaching of Engineering Mechanics encountered various problems, such as the failure of rain classroom login caused by network congestion, the serious frame loss of Tencent classroom live broadcast and the failure to refresh online platform resources. Therefore, if only relying on the use of a single intelligent teaching tool and online teaching platform, the emergency response ability for emergencies such as network congestion is slightly insufficient.
(3) The quality and authenticity of online learning need to be improved

The construction of online teaching mode of Engineering Mechanics needs to be carried out online by mobile phone and computer client, but there are some loopholes. For example, in the online selfregulated learning process, some students simply brush times and hang up to watch learning videos in order to complete tasks, which increases the learning time, while online training, testing and homework still can not avoid students' plagiarism; During the online live broadcast, some students may use mobile phones and tablets to carry out activities unrelated to classroom learning while participating in computers and notebooks. Therefore, the quality and authenticity of Engineering Mechanics online learning need to be improved.

(4) Restriction of engineering mechanics experiment

The experimental teaching of engineering mechanics is an important link in the teaching of engineering mechanics. Through the experimental teaching, students can better understand the relevant theoretical knowledge of mechanics, which is conducive to cultivating students' innovative thinking and improving their practical ability [4]. Students can not deeply experience the experimental process of engineering mechanics through online learning. Relying only on online explanation, animation video materials and virtual experiment is not conducive to cultivating students' innovative thinking and practical ability. Therefore, the engineering mechanics experiment in the spring of 2020 is adjusted to be carried out after returning to school in the autumn.

\subsection{Opportunity of Online Teaching Mode of Engineering Mechanics}

\section{(1) Policy support for educational informatization}

Some documents all attach great importance to the issue of education informatization, put forward the 《Education Informatization 2.0 Action Plan 》, implement the 《Accelerate the Advancement of Education Informatization Action》, actively develop "Internet + Education", give full play to the advantages of online education and artificial intelligence, and innovate education and learning methods, accelerate the development of a more open and flexible education system for everyone, suitable for everyone, and build a learning society. The support of education informatization related policies has played a good role in assisting and promoting the construction of the online teaching mode of engineering mechanics. 
(2) The popularization of the Internet and the innovation and development of smart teaching tools and online platforms

The popularization of network is a key step in the development of online education. In the future, the popularization and application of $5 \mathrm{G}$ network in the country will greatly improve the applicability of the online teaching mode of engineering mechanics. The continuous innovation and development of intelligent teaching tools and online platforms will also greatly contribute to educational informatization by collecting user experience and suggestions. The integrated application of VR and AR visualization technology will enrich and improve online teaching.

\subsection{Challenges of The Online Teaching Mode of Engineering Mechanics}

\section{(1) Design and organization of teaching}

The construction of online teaching mode of Engineering Mechanics relies on the comprehensive application of intelligent teaching tools and online teaching platform, online live broadcasting, online autonomous learning, online data sharing and learning feedback, course test detection and homework training, etc The new multi-dimensional and integrated online teaching mode of Engineering Mechanics needs a variety of intelligent teaching tools and online teaching platforms to be reasonably coordinated and used in the whole process of "pre class, in class and after class". Therefore, the effective design and organization of Engineering Mechanics online teaching is conducive to the cooperation of various intelligent teaching tools and online platforms in the whole process of teaching activities. According to the course content and characteristics, whether to select appropriate teaching resources and re design and organize the teaching of "pre class, in class and after class" on the premise of integrating intelligent teaching tools will directly affect the quality of online teaching of engineering mechanics.

(2) Data screening and analysis

With the help of online live background data, rain classroom background data and the real-time collection of students' learning data on the online teaching platform, the feedback of students' objective learning data in the whole process can be obtained, and the large amount of feedback data also puts forward higher requirements for teachers' ability to screen and analyze data. How to adjust teachers' teaching design and organization through analysis according to the selected data is also a challenge for teachers themselves.

\section{PRACTICAL SUGGESTIONS FOR THE ONLINE TEACHING MODE OF ENGINEERING MECHANICS}

(1) Improvement of teachers' information technology literacy

The construction of Engineering Mechanics online teaching mode requires teachers to have good information technology literacy. Therefore, teachers should strengthen their own learning, be familiar with the operation and use of various intelligent teaching tools and online teaching platforms, and actively participate in various information technology training to improve their own information technology literacy and ability. Secondly, according to the characteristics of the course, flexibly select various intelligent teaching tools and online platforms to improve the effect of online teaching of engineering mechanics.

(2) The improvement of teachers' teaching level

The online teaching mode of Engineering Mechanics requires teachers to have a good teaching organization and design for the course. In the process of online teaching organization and design, teachers should consider the assistance and integration of intelligent teaching tools and online platform. Only with the continuous improvement of teachers' teaching level, can they better base on students' learning characteristics and integrate scenario simulation, task driven group discussion and other teaching methods can make better use of intelligent teaching tools and platforms to improve students' learning initiative and enthusiasm. In addition, teachers should add humanistic education and ideological and political education elements in online teaching, strengthen the emotional interaction in online classroom, and enhance the sense of participation of both sides of teaching[5].

\section{IMPLEMENTATION EFFECT AND CONCLUSION}

After the online teaching mode teaching practice of Engineering Mechanics Course in the spring of 2020, the impact of Engineering Mechanics online teaching mode on students' learning process and effect is analyzed by means of Tencent classroom teacherstudent interaction, rain classroom questionnaire survey and online platform teaching evaluation feedback and posting messages, combined with the feedback of students' objective learning data in the whole process. According to the analysis results, students have obtained a better learning experience, the learning effect has been significantly improved, and students' autonomous learning ability has been improved.

Aiming at novel coronavirus pneumonia during the period of the suspension of teaching, the paper takes the engineering mechanics online teaching mode as an 
example, and based on the SWOT analysis method, conducts a comprehensive and systematic study on the online teaching mode of engineering mechanics from four aspects: strengths, weaknesses, opportunities and challenges. Based on the findings, it puts forward practical suggestions for the online teaching mode of engineering mechanics. It provides experience and reference for further promoting the improvement and development of online teaching mode.

\section{ACKNOWLEDGMENT}

This work was financially supported by the Youth Foundation of Shandong Technology and Business University No. 2015QN014, and the PhD Research Startup Foundation of Shandong Technology and Business University No. BS201522.

\section{REFERENCES}

[1] Zhang Li, Liu Jian, Sun Bo, et al. Exploration and thinking of online physiology teaching mode under the novel coronavirus epidemic [J]. medical education research and practice, vol. 028 (002), 2020, pp. 221-224.

[2] Wang Shaolian. "Four Understandings" to be clarified in online teaching $[\mathrm{J}]$. Basic Education Curriculum, vol. 271(07), 2020, pp: 46-50.

[3] Guo Wenjie, Huang Yangjun. Teaching reform of engineering mechanics based on MOOC [J]. Western quality education, vol. 6 (05),2020, pp. 133-134.

[4] Dong Yu, Li Lifeng, Shi Junwei, et al. Research on experimental teaching reform of engineering mechanics under the training mode of applied talents $[\mathrm{J}]$. China modern educational equipment, vol. 15, 2018, pp. 88-89.

[5] Chai Yuanyuan, Wang Weiguo. Exploration of online teaching mode based on Tencent conference and rain classroom $[\mathrm{J}]$. Computer education, vol. 311 (11), 2020, pp. 52-56 